\title{
Molecular cloning, expression, and regulation of the ovalbumin gene in pigeon oviduct epithelial cells
}

\author{
H. Zhang ${ }^{1,2}$, L.Z. Lu' ${ }^{2}$, L. Chen ${ }^{2}$, Z.R. Tao ${ }^{2}$, F. Chen ${ }^{1,2}$, S.L. Zhong', \\ Y.L. Liu ${ }^{1,2}$, Y. Tian ${ }^{2}$ and P.S. Yan ${ }^{1}$ \\ ${ }^{1}$ College of Animal Sciences and Technology, Nanjing Agriculture University, \\ Nanjing, Jiangsu, China \\ ${ }^{2}$ Institute of Animal Husbandry and Veterinary Science, \\ Zhejiang Academy of Agricultural Sciences, Hangzhou, Zhejiang, China \\ ${ }^{3}$ Ping Yang XingLiang Pigeon Farming Co. Ltd., Wenzhou, Zhejiang, China \\ Corresponding author: P.S. Yan \\ E-mail: yanps@njau.edu.cn
}

Genet. Mol. Res. 13 (1): 117-126 (2014)

Received November 21, 2012

Accepted September 4, 2013

Published January 10, 2014

DOI http://dx.doi.org/10.4238/2014.January.10.2

\begin{abstract}
The full-length pigeon ovalbumin (OVA) gene cDNA was cloned and sequenced by reverse transcription-polymerase chain reaction (RT-PCR) and rapid-amplification of cDNA ends. A 386-amino acid protein was predicted for the obtained sequence, which had $67 \%$ identity with the chicken protein. Similar to chicken OVA, the pigeon OVA gene is a non-inhibitory serine protease inhibitor. Quantitative PCR analysis revealed that pigeon OVA mRNA was highly expressed in the oviduct, and trace amounts were detected in other tissues. During the reproductive cycle, pigeon oviduct OVA mRNA expression reached its peak during the egg-laying stage, decreased with brooding, and then increased again during the squabfeeding period. Moreover, the relative OVA expression level in
\end{abstract}


pigeon oviduct epithelial cells could be upregulated by a constant concentration of steroid hormones.

Key words: Pigeon; Ovalbumin expression; Ovalbumin regulation; Pigeon oviduct epithelial cells; Steroid hormones

\section{INTRODUCTION}

Ovalbumin (OVA) is a member of the serine protease inhibitor (SERPIN) superfamily (Stein et al., 1991; Hu and Du, 2000). Numerous SERPINs control proteolytic cascades by inhibiting serine proteases (Whisstock et al., 2005). However, OVA does not inhibit protease activity because it fails to undergo the conformational change known as the "stressed to relaxed transition" (Gettins, 1989, 2002). OVA has been identified in a number of avian species, including chicken, emu, and quail (McReynolds et al., 1978; Yang et al., 2009; Maehashi et al., 2010). Chicken OVA, which is secreted from oviduct tubular gland cells, does not contain an N-terminal leader sequence (McReynolds et al., 1978; Robinson et al., 1986). The mRNA sequence of the quail OVA gene has also been cloned. Avian OVA share greater than 55\% identity at both the nucleotide and amino acid sequence levels; however, the cDNA sequence of pigeon OVA has not yet been reported.

In avian species, OVA, a primary protein of the albumin, provides nutrition for the developing embryo (Moran Jr., 2007). Moreover, transgenic technology provides the possibility of utilizing egg-laying avian species as a production platform for the large-scale synthesis of target proteins. Oviduct-specific transcription elements, particularly the OVA promoter, are interesting tools that may be used in the production of specific target proteins (Kwon et al., 2010). Avian oviduct bioreactors have been widely studied in biotechnology, in which foreign proteins were found to be mainly expressed in the oviduct (Lillico et al., 2007; Kwon et al., 2010; Byun et al., 2011). However, expression patterns of the pigeon OVA gene in different tissues are currently unclear, and whether it is specifically expressed in the oviduct remains unknown.

Like many wild birds, the pigeon reproductive cycle includes three stages: the egglaying period, the incubation period, and the squab-feeding period. Furthermore, a large number of pigeons have been raised in captivity throughout the world. Therefore, the pigeon is an ideal animal model for the study of altrice reproductive characters. In vitro, the serum physiological indices of pigeons are correlated with breeding status (Dong et al., 2012). Palmiter and Wren (1971) showed that sexually immature chicken oviducts treated with estrogen showed an 8 -fold increase in wet weight. Massive amounts of cells proliferate in oviduct epithelia in response to estrogen (Dougherty and Sanders, 2005). However, whether any relationship exists between pigeon OVA mRNA expression and breeding stages remains unclear.

Several steroid hormones are involved in the regulation of chicken OVA mRNA transcription in the chicken oviduct (McKnight and Palmiter, 1979; Sanders and McKnight, 1985). In the chicken OVA gene, two major regulatory elements at the 5'-flanking region coordinate regulation of the OVA gene: the steroid-dependent regulatory element (SDRE) and the negative regulatory element (NRE). The SDRE and NRE each contain several functional subdomains, which bind to specific transcription factors that can activate or repress OVA gene transcription (Dillner and Sanders, 2002). Whether steroid hormones play a similar role in pigeon oviduct epithelial cells (POECs), and the concentration of steroid hormone that is necessary for enhancement of OVA mRNA expression remains unknown. 
The main purpose of this study was to amplify the full-length pigeon OVA cDNA, determine its expression in various tissues, measure OVA mRNA expression changes in the pigeon oviduct during different breeding stages, and determine whether OVA expression is regulated by steroid hormones in POECs.

\section{MATERIAL AND METHODS}

\section{Pigeon population and sample collection}

One 2-year-old King pigeon was used for OVA cDNA cloning and sequencing. Five 2-year-old female King pigeons were used for quantitative polymerase chain reaction (qPCR) analysis. Three groups of female pigeons (2 years old) were used to measure OVA expression changes in pigeon oviducts at different breeding stages: I) egg-laying (one day after laying the first egg), II) incubating (fifth day of incubation), and III) squab-feeding (fifth day of feeding squab). Each group consisted of 4 female pigeons.

Fifteen tissues (oviduct, ovary, heart, liver, spleen, lung, kidney, abdominal fat, stomach, skeletal muscle, hypothalamus, brain, intestine, craw, and pancreas) were collected, immediately frozen in liquid nitrogen, and then stored at $-70^{\circ} \mathrm{C}$ until total RNA extraction. All pigeons were cared for under guidelines comparable to those established by the Canadian Council on Animal Care.

\section{Total RNA extraction and reverse transcription}

Total RNA was extracted using TRIzol ${ }^{\circledR}$ reagent (Takara, Osaka, Japan) according to manufacturer protocols and treated with recombinant DNase I (Takara). cDNA for rapid amplification of cDNA ends (RACE) was synthesized using the SMART ${ }^{\mathrm{TM}}$ RACE cDNA Amplification Kit (Clontech). M-MLV reverse transcriptase (Takara) was used to synthesize cDNA for use in qPCR.

\section{Cloning of the full-length pigeon OVA gene}

Five primer pairs were used in this study (Table 1). The cDNA that was reverse transcribed from oviduct RNA was used as the template, and a pigeon OVA gene fragment was amplified using the primer pair OVAF1/R1. PCR was performed using $2 \mu \mathrm{L}$ cDNA in a mixture containing $20 \mu \mathrm{L} 1 \mathrm{U}$ Ex-Taq polymerase (Takara), $160 \mu \mathrm{M}$ of each dNTP, and $4 \mu \mathrm{L} 5 \mathrm{X}$ buffer supplied by the manufacturer. The PCR conditions were $5 \mathrm{~min}$ at $94^{\circ} \mathrm{C}$, followed by 32 cycles of $30 \mathrm{~s}$ at $94^{\circ} \mathrm{C}, 60 \mathrm{~s}$ at $56^{\circ} \mathrm{C}$, and $45 \mathrm{~s}$ at $72^{\circ} \mathrm{C}$. After a 10 -min final extension at $72^{\circ} \mathrm{C}$, the products were visualized on $1.0 \%$ agarose gel using SYBR Green I (Invitrogen staining).

Pigeon OVA gene full-length cDNA was obtained using RACE with the SMART RACE cDNA Amplification Kit (Clontech) following manufacturer protocols. For the template, $1 \mu \mathrm{g}$ total RNA obtained from the oviduct was used. 5'-RACE and 3'-RACE were performed with gene-specific primers O5GSP and O3GSP independently. The 5'- and 3'-cDNA fragments obtained from RACE were cloned into a PMD-19T plasmid vector (Takara) and sequenced by Invitrogen. 
Table 1. Detail information of primer pairs and OVA-siRNA.

\begin{tabular}{|c|c|c|c|c|}
\hline Primer & Binding sites & Nucleotide sequence (5'-3') & Size (bp) & $\mathrm{Ta}\left({ }^{\circ} \mathrm{C}\right)$ \\
\hline OVAF1 & nt357-374a & ACAATGTGTGAAGGAACT & 798 & 56 \\
\hline OVAR1 & nt1137-1154a & GAAATGCATCTGCCAAAG & & \\
\hline O5GSP & $\mathrm{nt} 492-518^{\mathrm{b}}$ & TGACAGTTTCCACGCTTTCTTTATACA & 518 & 70 \\
\hline O3GSP & nt1093-1117 b & TGAAGCTGTTCATCAGGCATTTGTT & 341 & 68 \\
\hline OVAdF & nt203-219 b & ATCTTCGCCCCCTTGAG & 235 & 60 \\
\hline OVAdR & nt $420-437^{b}$ & CGTGAAGTCTGGCAAAGC & & \\
\hline$\beta$-actinF & $\mathrm{nt} 558-577^{\mathrm{c}}$ & CCCATCTACGAAGGCTACGC & 250 & 60 \\
\hline$\beta$-actinR & nt $687-707^{\circ}$ & CTTGATGTCACGCACAATTTC & & \\
\hline
\end{tabular}

${ }^{\mathrm{a} B a s e d}$ on reported turkey OVA sequence (accession No. AF064546.1). ${ }^{\mathrm{b}}$ Based on the obtained pigeon OVA sequence (accession No. NM_205152). 'Based on reported gallus $\beta$-actin cDNA sequence (accession No. NM_205518.1). $\mathrm{Ta}=$ annealing temperature.

\section{Sequence alignment}

Pigeon OVA amino acid sequences were predicted based on the open reading frames of the cDNA sequences (http://www.ncbi.nlm.nih.gov/gorf/gorf.html). The transmembrane segments were detected using the Softberry program (http://inux1.softberry.com/berry.phtml). The reactive center loop (RCL) was detected with BLAST (http://blast.ncbi.nlm.nih.gov/Blast. cgi). Amino acids sequences were aligned by the CLUSTAL X version 2.0 software.

\section{Cell culture}

POECs were isolated using methods described in Jung et al. (2011) and Kasperczyk et al. (2012), with some modifications. Oviduct tissue was collected from a 10-month-old laying-period pigeon that had not been stimulated with hormones. The pigeon's infundibulum and magnum oviduct segments were dissected and carefully removed from the surface of the oviduct, taking care to remove the mucosa and blood vessels. The manicured tissue was washed in phosphate-buffered saline with antibiotics (200 U penicillin $+200 \mathrm{U}$ streptomycin) and then cut into $1-2-\mathrm{mm}^{3}$ pieces. We then digested the pieces with $1 \mathrm{mg} / \mathrm{mL}$ collagenase type I for $50 \mathrm{~min}$ at $37^{\circ} \mathrm{C}$ in a shaking water bath. The dissociated cells were filtered through a 150- $\mu \mathrm{m}$ copper sieve. The filtered cells were centrifuged at $1000 \mathrm{rpm}$ for $8 \mathrm{~min}$ and washed in Dulbecco's modified Eagle's medium (DMEM)F12. The differential adhesion method was used to obtain purified POECs. The cells were seeded on 24-well cell culture plates at a density of $4 \times 10^{6}$ cells $/ \mathrm{cm}^{2}$. Purified POECs were cultured in DMEM-F12 (Invitrogen) containing 10\% fetal bovine serum, antibiotic (100 U penicillin +100 U streptomycin), $40 \mathrm{ng} / \mathrm{L}$ epidermal growth factor, $20 \mu \mathrm{g} / \mathrm{L}$ insulin, and $10 \mu \mathrm{M}$ glutamine in an incubator with $5 \% \mathrm{CO}_{2}$ at $37^{\circ} \mathrm{C}$. Progesterone $\left(\mathrm{P}_{4}\right), 17 \beta$-estradiol $\left(\mathrm{E}_{2}\right)$, and cortisol (Cort) were added to the medium to assess the effect of steroid hormones on pigeon OVA expression.

\section{qPCR analysis}

qPCR was employed to determine OVA mRNA levels using the ABI 7300 system (Applied Biosystems, Foster City, CA, USA) and THUNDERBIRD SYBR qPCR Mix (Toyobo, Osaka, Japan). Assays were performed in a $20-\mu \mathrm{L}$ reaction system containing 5 $\mu \mathrm{L}$ cDNA template, $10 \mu \mathrm{L}$ THUNDERBIRD SYBR qPCR Mix, $0.4 \mu \mathrm{L}$ ROX reference dye (Toyobo), and $0.4 \mathrm{mM}$ primers (OVAdF/R for the target gene and actinF/R for the control, 
$\beta$-actin). The OVA and $\beta$-actin primer sequences were obtained from the National Center for Biotechnology Information (NCBI). Thermal cycler parameters were as follows: $94^{\circ} \mathrm{C}$ for $2 \mathrm{~min}, 40$ cycles of denaturation at $94^{\circ} \mathrm{C}$ for $10 \mathrm{~s}$, and annealing and extension at $60^{\circ} \mathrm{C}$ for $30 \mathrm{~s}$. Pure water replaced the template as the negative control and each sample reaction was repeated three times. The relative expression levels of the pigeon OVA gene were determined using the $2^{-\Delta \mathrm{Ct}}\left(\Delta \mathrm{Ct}=\mathrm{Ct}_{\text {target gene }}-\mathrm{Ct}_{\beta \text {-actin }}\right)$ method. Data are reported as means $\pm \mathrm{SE}$.

\section{qPCR efficiency and statistical analysis}

The efficiency of amplification of each primer used in the qPCR was estimated by the step dilutions. A standard curve with a five-point 10 -fold dilution series was used to calculate amplification efficiency using the following formula: $\mathrm{E}=10^{-1 / \text { slope-1 }}$.

Significant differences in expression levels were evaluated using the Student $t$-test. Differences were considered to be significant at values of $\mathrm{P}<0.05$.

\section{RESULTS}

\section{cDNA cloning and sequence analysis}

The full-length pigeon OVA cDNA cloned by transcription-PCR and RACE was found to be $1433 \mathrm{bp}$ in length (GenBank accession No. JQ345718), and consisted of a 118bp 5'-untranslated region (UTR) and a 157-bp 3'-UTR with a poly-(A) tail of 29 nucleotides. The deduced pigeon OVA protein, 386 amino acids in length, had $67 \%$ identity with the corresponding protein in chicken (Figure 1). The RCL was found in the pigeon OVA protein by BLAST (http://www.ncbi.nlm.nih.gov/BLAST). In addition, as in other avian OVA, no signal peptide was predicted in pigeon OVA.

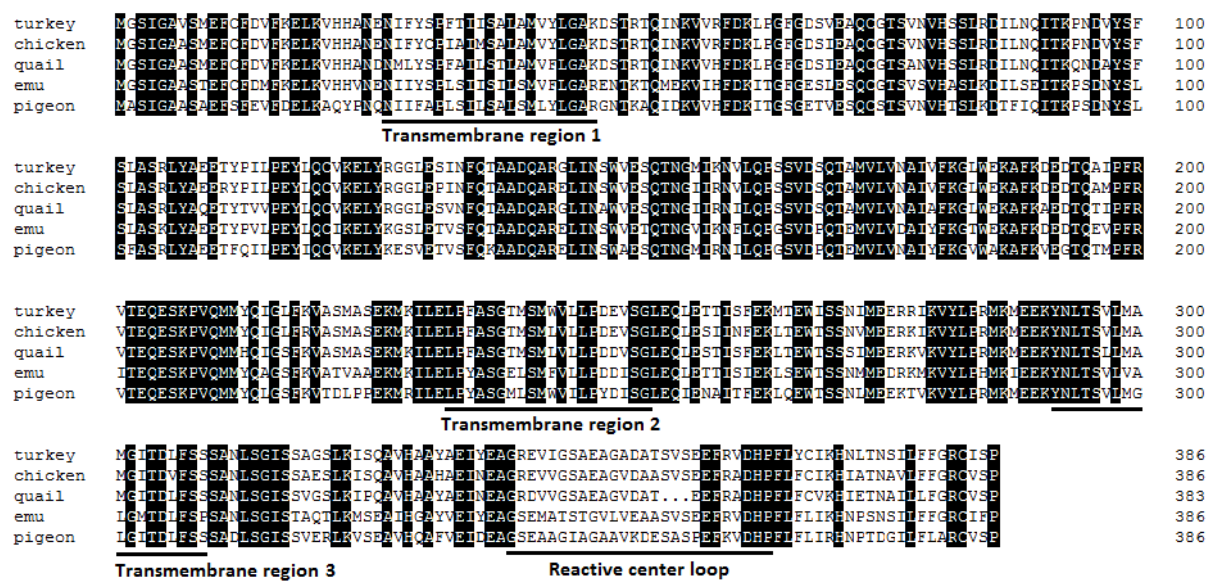

Figure 1. Comparison of the amino acid sequences of OVA in emu, turkey, quail, chicken, and pigeon. The OVA sequences of emu (BAJ23166), turkey (XP_003204842), quail (AAQ22769), and chicken (AAA48998) were downloaded from NCBI protein database [http://www.ncbi.nlm.nih.gov/]. (-) indicates deletion of an amino acid. The shadow regions indicate conservative amino acids among the five species. The transmembrane region and the reactive center loop domain are shown underlined. 


\section{Pigeon OVA expression pattern in various tissues}

Pigeon OVA gene expression was detected in various tissues by qPCR with the $\mathrm{OVAdF} / \mathrm{R}$ primer pair. The $\mathrm{OVAdF} / \mathrm{R}$ and actinF/R amplification efficiencies are displayed in Figure 2A and B. All primers exhibited proper amplification efficiencies: 0.9216 for OVAdF/R and 0.9454 for actinF/R. Figure 3 shows that the pigeon OVA gene was most highly expressed in the oviduct, and trace amounts were detected in other tissues.
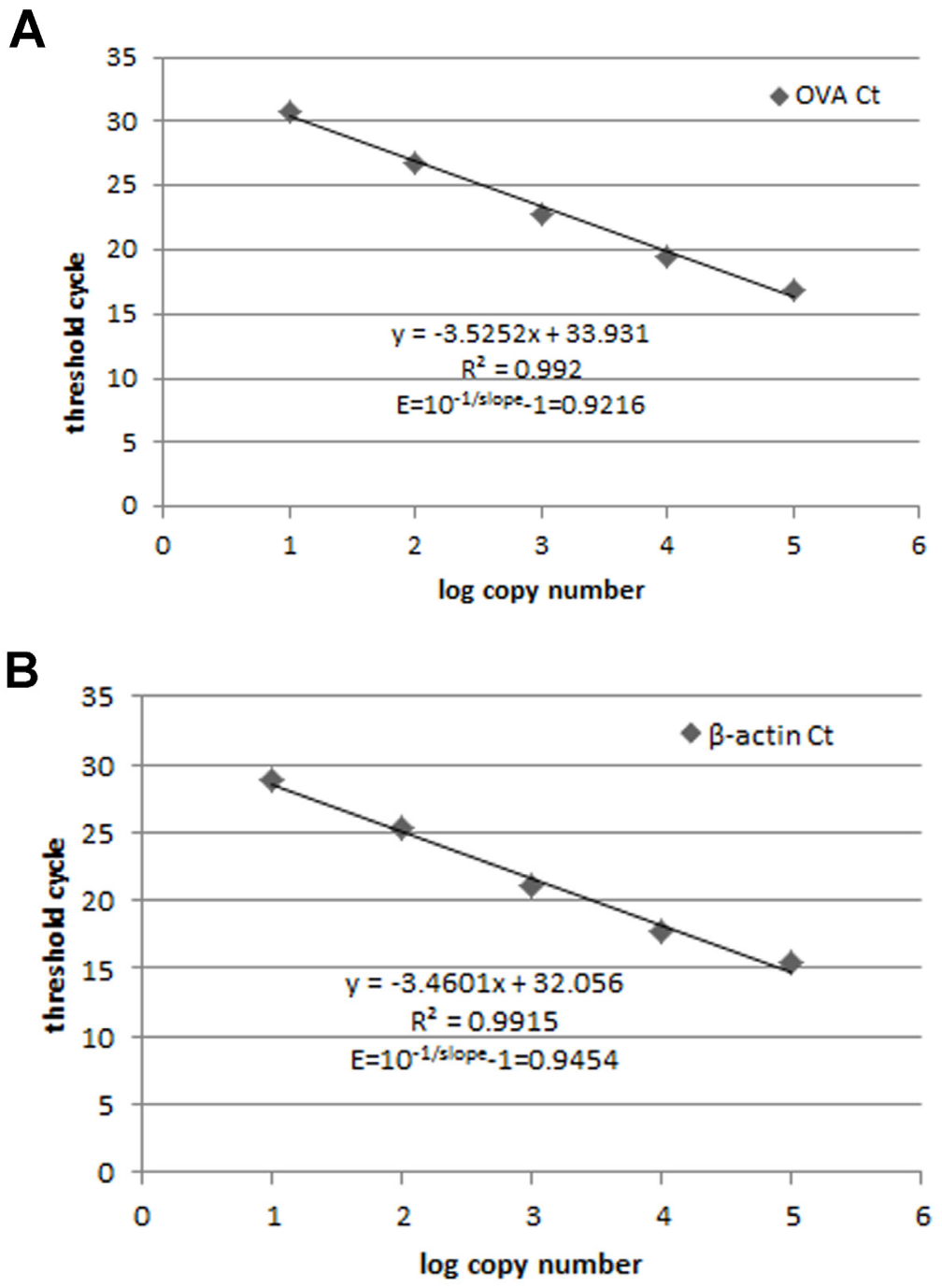

Figure 2. Relative standard curves. A. and B. Standard curves generated by plotting cycles at threshold fluorescence (Ct) against the logarithmic values of liver cDNA amounts (means $\pm \mathrm{SE} ; \mathrm{N}=3$ ). Quantities of oviduct cDNA are reported as dilution factors of the cDNA preparation $\left(1,10^{-1}, 10^{-2}, 10^{-3}\right.$, and $\left.10^{-4}\right)$. Correlation coefficients $\left(\mathrm{R}^{2}\right)$ and amplification efficiencies (E) of different primer pairs are shown in the figure. 


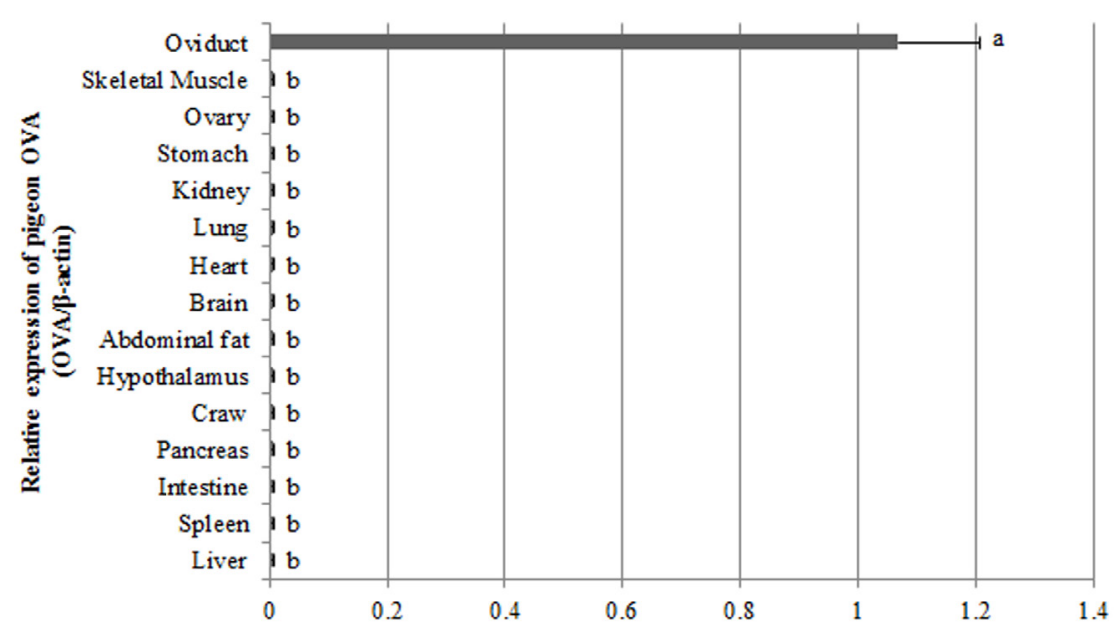

Figure 3. Relative pigeon OVA mRNA expression levels in various tissues, including oviduct, testis, brain, ovary, hypothalamus, skeletal muscle, spleen, craw, stomach, lung, kidney, and heart. Pigeon OVA gene expression was normalized to $\beta$-actin. Each column represents the mean of five female pigeons (means $\pm \mathrm{SE}$ ). Different letters $\mathrm{P}<0.05$.

\section{Changes in oviduct OVA mRNA expression}

Egg-laying birds had the highest OVA mRNA expression compared to those in other reproductive stages. Compared with the breeding stage, OVA mRNA expression increased again after the squabs hatched. There were significant differences in OVA mRNA expression over the reproductive cycle (Figure 4).

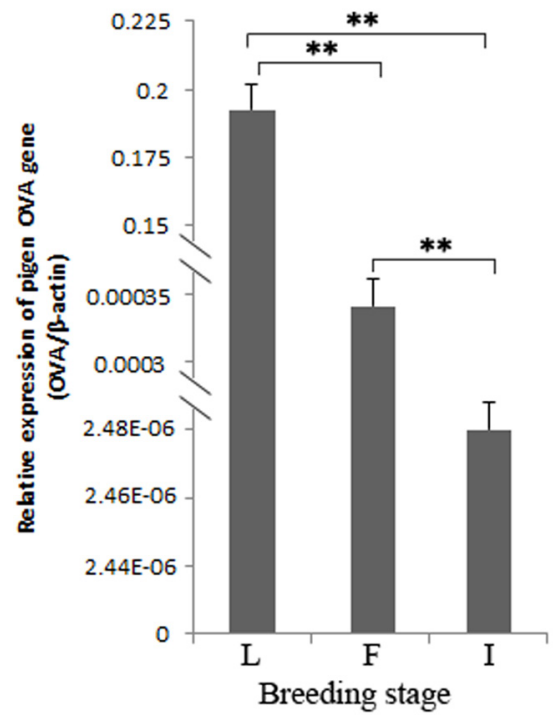

Figure 4. Profiles and oviduct OVA mRNA expression in the oviduct of female pigeons associated with breeding stage. The OVA gene expression level was normalized to that of $\beta$-actin. Each bar represents the $2^{-\Delta C t}$ value of 4 individual pigeons $\pm \mathrm{SE}$. $* * \mathrm{P}<0.01$. $\mathrm{L}=$ egg-laying period; $\mathrm{F}=$ squab-feeding period; $\mathrm{I}=$ incubation period. 


\section{Effect of $E_{2}, P_{4}$, and Cort on OVA gene expression}

To investigate the response of POECs to hormones, we treated POECs with Cort, $\mathrm{E}_{2}$, and $\mathrm{P}_{4}$ for $24 \mathrm{~h}$. The working concentrations of each steroid hormone were $10^{-6}, 10^{-8}$, and $10^{-10}$ $\mathrm{M}$, respectively (Figure 5). Compared with the control, administration of $10 \mathrm{nM}$ Cort for $24 \mathrm{~h}$ increased pigeon OVA mRNA by $1.5(\mathrm{P}<0.05)$, administration of $1 \mu \mathrm{M} \mathrm{E}_{2}$ for $24 \mathrm{~h}$ increased pigeon OVA mRNA by $56 \%(\mathrm{P}<0.05)$, and administration of $1 \mu \mathrm{M} \mathrm{P} \mathrm{P}_{4}$ for $24 \mathrm{~h}$ increased pigeon OVA mRNA by $1.87(\mathrm{P}<0.05)$.

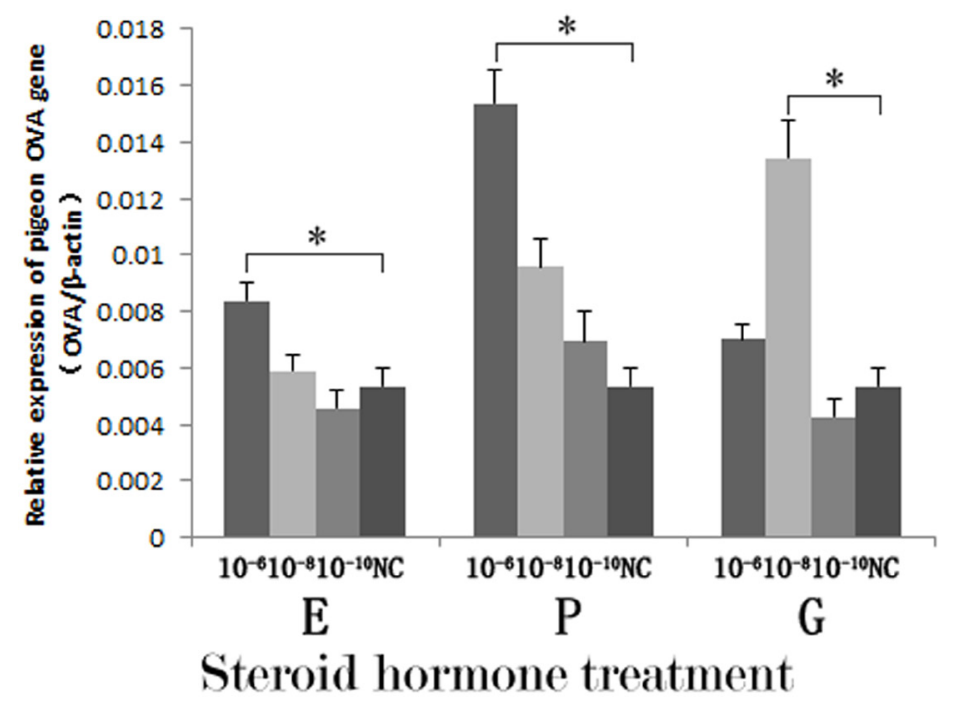

Figure 5. Effects of estrogen $\left(\mathrm{E}_{2}\right)$, progesterone $\left(\mathrm{P}_{4}\right)$, and cortisol (Cort) on the abundance of the pigen oviduct epithelial cell OVA mRNA. The working concentrations of these steroid hormones are 0 (negative control, NC), $10^{-6}, 10^{-8}$ and $10^{-10} \mathrm{M}$, respectively. Pigeon OVA expression was determined by qPCR, and the $\beta$-actin was used as a reference gene. Results are reported as means $\pm \mathrm{SE}$ of triplicate cultures. $* \mathrm{P}<0.05$.

\section{DISCUSSION}

In this study, we cloned and sequenced pigeon OVA cDNA. The pigeon OVA gene displays homology to those of chicken, quail, and emu (McReynolds et al., 1978; Yang et al., 2009; Maehashi et al., 2010). The ovalbumin was a 38-amino acid peptide. According to our computational analysis (ProtComp Version 9.0, Softberry), it is an extracellular secretory protein with 3 transmembrane segment residues: 27-47, 233-252, and 292-309. As in quail, pigeon OVA gene transmembrane segments may be involved in the membrane translocation machinery, which facilitates transport across the membrane (Yang et al., 2009). As a SERPIN, pigeon OVA also contains an RCL, which is required for its inhibitory function. Based on the amino acid sequence, the pigeon OVA gene belongs to the ovalbumin-like subfamily.

OVA mRNA was detected in a range of pigeon tissues (i.e., oviduct, ovary, spleen, skeletal muscle, craw, stomach, brain, lung, kidney, and heart). Similar to previous studies on chicken, the pigeon OVA gene appeared to be highly expressed in the oviduct, where it can be 
translated into ovalbumin. As has been observed in studies of transgenic hens (Kwon et al., 2010), the expression in other tissues was very low.

With respect to changes during the breeding cycle, the estrogen level of egg-laying pigeons is higher than that of incubating pigeons (Dong et al., 2012). Here, we concluded that during the egg-laying period, pigeon OVA mRNA expression was triggered by the elevated serum steroid hormone concentration. Of the entire pigeon reproduction cycle, OVA expression is lowest during the incubation period. This may be because the low estrogen (Dong et al., 2012) and high prolactin levels inhibit gonad function (Buntin and Tesch, 1985) during this period.

Chicken OVA expression levels are regulated by specific transcription factors and steroid hormones (McKnight, 1978; Dillner and Sanders, 2002). In chicken oviduct epithelial cells, the hormones $\mathrm{E}_{2}, \mathrm{P}_{4}$, and Cort could upregulate OVA mRNA expression (McKnight and Palmiter, 1979). Combination treatment with $10^{-7} \mathrm{M} \mathrm{E}_{2}$ and $10^{-8} \mathrm{M}$ Cort upregulated expression in chicken (Sanders and McKnight, 1985). In this study, we also found that $\mathrm{E}_{2}, \mathrm{P}_{4}$, and Cort stimulated pigeon OVA gene expression. This finding provides new insights into the regulation of OVA by steroid hormones. According to results of chicken studies, exogenous steroid hormones are essential for cell proliferation of the oviduct (Dougherty and Sanders, 2005), and OVA gene expression is related to this proliferation process. Results of the present study suggest that steroid hormones are possibly playing similar roles in POECs.

In conclusion, the pigeon OVA gene was cloned, sequenced, and found to be expressed predominantly in the oviduct. Pigeon oviduct OVA mRNA expression differed according to breeding stage: expression peaked during the egg-laying stage, decreased with brooding, and then increased again during the squab-feeding period. Moreover, our data suggest that OVA gene expression is regulated by the constant concentration of steroid hormones in POECs.

\section{ACKNOWLEDGMENTS}

Research supported by the Science and Technology Specific Project for Enriching People and Strengthening County Economy, China, and the Breeding Specific Project of the "Twelfth Five Plan" of Zhejiang Province, China (project \#2012C12906-17).

\section{REFERENCES}

Buntin JD and Tesch D (1985). Effects of intracranial prolactin administration on maintenance of incubation readiness, ingestive behavior, and gonadal condition in ring doves. Horm. Behav. 19: 188-203.

Byun SJ, Kim SW, Kim KW, Kim JS, et al. (2011). Oviduct-specific enhanced green fluorescent protein expression in transgenic chickens. Biosci. Biotechnol. Biochem. 75: 646-649.

Dillner NB and Sanders MM (2002). The zinc finger/homeodomain protein deltaEF1 mediates estrogen-specific induction of the ovalbumin gene. Mol. Cell Endocrinol. 192: 85-91.

Dong XY, Zhang M, Jia YX and Zou XT (2012). Physiological and hormonal aspects in female domestic pigeons (Columba livia) associated with breeding stage and experience. J. Anim. Physiol. Anim. Nutr. [Epub ahead of print].

Dougherty DC and Sanders MM (2005). Estrogen action: revitalization of the chick oviduct model. Trends Endocrinol. Metab. 16: 414-419.

Gettins P (1989). Absence of large-scale conformational change upon limited proteolysis of ovalbumin, the prototypic serpin. J. Biol. Chem. 264: 3781-3785.

Gettins PG (2002). Serpin structure, mechanism, and function. Chem. Rev. 102: 4751-4804.

Hu HY and Du HN (2000). Alpha-to-beta structural transformation of ovalbumin: heat and pH effects. J. Protein Chem. 19: 177-183. 
Jung JG, Park TS, Kim JN, Han BK, et al. (2011). Characterization and application of oviductal epithelial cells in vitro in Gallus domesticus. Biol. Reprod. 85: 798-807.

Kasperczyk K, Bajek A, Joachimiak R, Walasik K, et al. (2012). In vitro optimization of the Gallus domesticus oviduct epithelial cells culture. Theriogenology 77: 1834-1845.

Kwon SC, Choi JW, Jang HJ, Shin SS, et al. (2010). Production of biofunctional recombinant human interleukin 1 receptor antagonist (rhIL1RN) from transgenic quail egg white. Biol. Reprod. 82: 1057-1064.

Lillico SG, Sherman A, McGrew MJ, Robertson CD, et al. (2007). Oviduct-specific expression of two therapeutic proteins in transgenic hens. Proc. Natl. Acad. Sci. U. S. A. 104: 1771-1776.

Maehashi K, Matano M, Irisawa T, Uchino M, et al. (2010). Primary structure of potential allergenic proteins in emu (Dromaius novaehollandiae) egg white. J. Agric. Food Chem. [Epub ahead of print].

McKnight GS (1978). The induction of ovalbumin and conalbumin mRNA by estrogen and progesterone in chick oviduct explant cultures. Cell 14: 403-413.

McKnight GS and Palmiter RD (1979). Transcriptional regulation of the ovalbumin and conalbumin genes by steroid hormones in chick oviduct. J. Biol. Chem. 254: 9050-9058.

McReynolds L, O’Malley BW, Nisbet AD, Fothergill JE, et al. (1978). Sequence of chicken ovalbumin mRNA. Nature 273: $723-728$.

Moran ET Jr (2007). Nutrition of the developing embryo and hatchling. Poult. Sci. 86: 1043-1049.

Palmiter RD and Wrenn JT (1971). Interaction of estrogen and progesterone in chick oviduct development. 3. Tubular gland cell cytodifferentiation. J. Cell Biol. 50: 598-615.

Robinson A, Meredith C and Austen BM (1986). Isolation and properties of the signal region from ovalbumin. FEBS Lett. 203: 243-246.

Sanders MM and McKnight GS (1985). Chicken egg white genes: multihormonal regulation in a primary cell culture system. Endocrinology 116: 398-405.

Stein PE, Leslie AG, Finch JT and Carrell RW (1991). Crystal structure of uncleaved ovalbumin at 1.95 A resolution. J. Mol. Biol. 221: 941-959.

Whisstock JC, Bottomley SP, Bird PI, Pike RN, et al. (2005). Serpins 2005 - fun between the beta-sheets. Meeting report based upon presentations made at the 4th International Symposium on Serpin Structure, Function and Biology (Cairns, Australia). FEBS J. 272: 4868-4873.

Yang S, Chen G, Yu X, Li M, et al. (2009). Cloning of a novel ovalbumin gene from quail oviduct and its heterologous expression in Pichia pastoris. J. Basic Microbiol. 49 (Suppl 1): S73-S78. 